\title{
Magnetometria aplicada na localização de artefatos metálicos
}

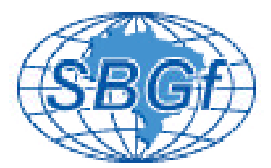

Vicente Luiz Galli, Wilson Shoji lyomasa e Valter Domingos da Silva

Instituto de Pesquisas Tecnológicas do Estado de São Paulo - IPT

Copyright 2004, SBGf - Sociedade Brasileira de Geofísica

Este texto foi preparado para a apresentação no I Simpósio de Geofísica da Sociedade Brasileira de Geofísica, São Paulo, 26-28 de setembro de 2004. Seu conteúdo foi revisado pela Comissão Tecno-científica do I SR-SBGf mas não necessariamente representa a opinião da SBGf ou de seus associados. E proibida a reprodução total ou parcial deste material para propósitos comerciais sem prévia autorização da SBG

\section{Resumo}

Ensaios geofísicos de magnetometria foram realizados em três áreas distintas do Estado de São Paulo para localizar objetos e estruturas de subsuperfície. No dique localizado no córrego do Ponunduva, município de Pirapora do Bom Jesus, SP, o levantamento foi realizado para localizar dois antigos dutos metálicos, utilizados para permitir o escoamento do córrego até o rio Tietê. Nas duas áreas do município de São Paulo, os trabalhos objetivavam a identificação de duto metálico da rede de distribuição de água e antiga fundação de uma construção civil. Nas três áreas, o método magnetométrico mostrou-se eficaz aos objetivos propostos.

\section{Introdução}

A necessidade em investigar e identificar objetos enterrados sem recorrer ao uso de método invasivo do terreno, como sondagens mecânicas, poços de inspeção, trincheiras, entre outros, vem crescendo devido a vários fatores: interferências entre redes de infra-estruturas; áreas urbanizadas; execução de obras em operação; etc São apresentados, neste trabalho, os resultados de levantamentos magnetométricos executados em três áreas distintas, sendo uma com objetivo de se encontrar um duto de ferro para escoamento de águas pluviais numa rua de São Paulo, outra para identificar a existência de fundação de uma antiga construção civil, e uma terceira, para localizar dois tubos metálicos sob um dique em Pirapora do Bom Jesus, utilizados para permitir o escoamento do córrego do Ponunduva até o rio Tietê. O que havia de comum nestas três áreas de estudo era a camada de aterro, composta por argila pouco arenosa de cor avermelhada (laterítica), sobre os artefatos metálicos. Os três alvos foram, inicialmente, investigados com o emprego do georadar, mas os resultados não permitiram identificar nenhum dos alvos pretendidos.

O método magnetométrico mostrou-se eficaz na localização dos artefatos metálicos, objeto desse trabalho.

\section{Trabalhos realizados}

Medidas da intensidade total do campo magnético foram adquiridas em intervalos de um metro em linhas paralelas, separadas entre $1 \mathrm{~m}$ e $5 \mathrm{~m}$, usando um magnetômetro de precessão nuclear Geometrics, modelo G-816, com sensibilidade de $1 \mathrm{nT}$. Foram elaborados mapas de contorno do campo magnético total e do sinal analítico. Os posicionamentos na superfície das fontes magnéticas causadoras das anomalias observadas foram obtidas por meio de deconvolução e inversão dos dados tanto em perfis como em mapas.

\section{Resultados}

As figuras 1, 2 e 3 ilustram os resultados obtidos nas três áreas investigadas.

\section{Magnetometria aplicada para localizar duto metálico para escoamento de água}

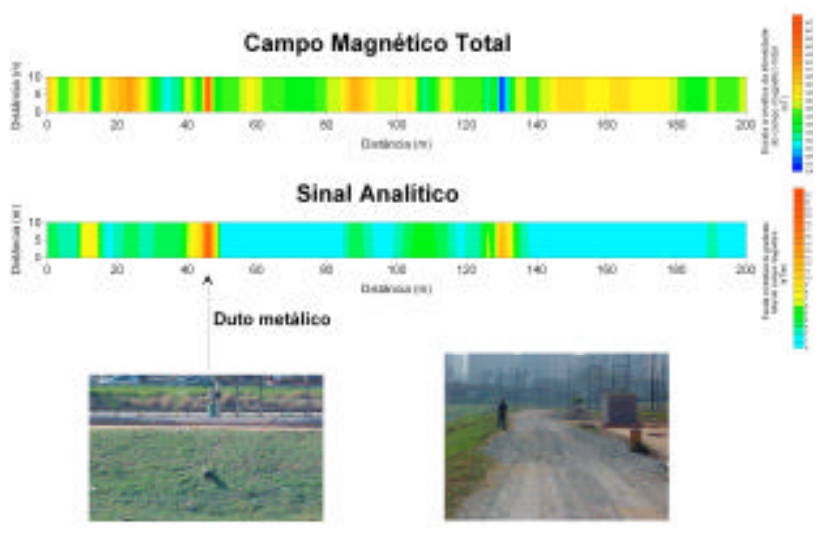

Figura 1 -Levantamento magnetométrico em rua de São Paulo para localizar duto metálico para escoamento de água. 


\section{Magnetometria aplicada para identificar a existência de fundação de uma construção em Săo Paulo}
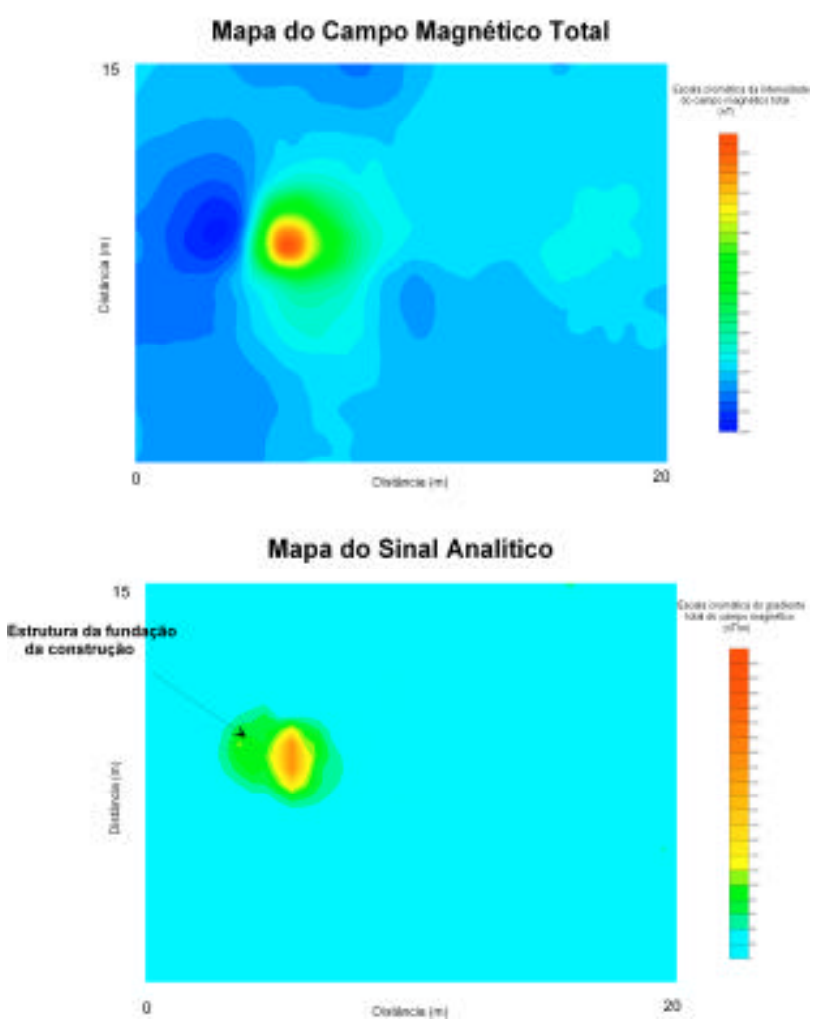

Figura 2 -Levantamento magnetométrico em São Paulo para localizar fundação de antiga construção civil.

\section{Magnetometria aplicada para localizar tubo metálico} sob um dique em Pirapora do Bom Jesus
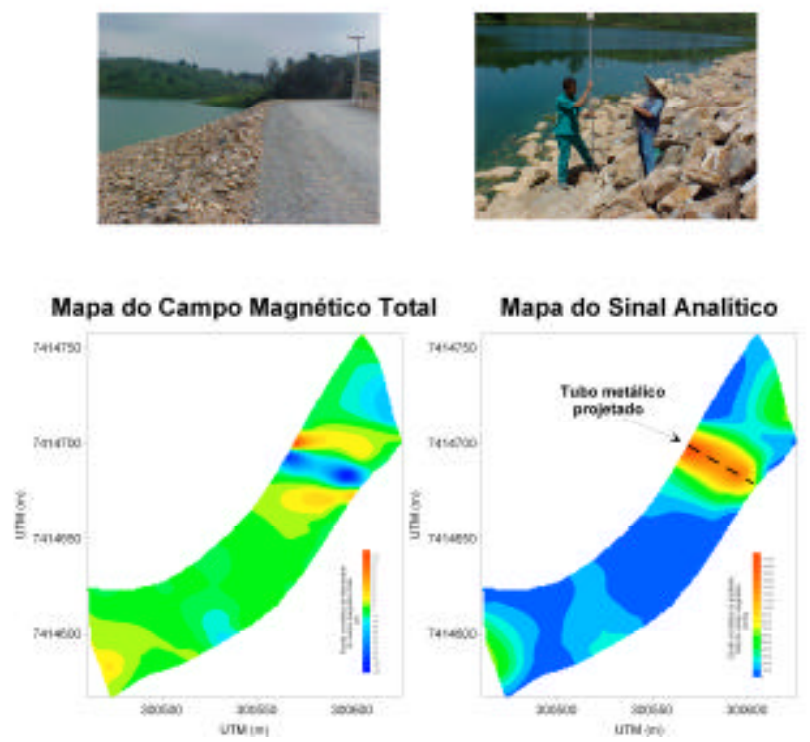

Figura 3 -Levantamento magnetométrico em Pirapora do Bom Jesus para localizar duto sob dique.

\section{Conclusões}

Nos três alvos estudados, foi possível localizar os artefatos metálicos, objeto da pesquisa, empregando-se o método magnetométrico que pode ser uma alternativa viável do ponto de vista técnico-econômico para situações semelhantes aos dos três casos estudados.

\section{Agradecimentos}

Celso Paiva - Galvão Engenharia

\section{Referências}

GRANT, F.S. AND WEST, G.F., 1965. Interpretation theory in applied geophysics. MacGraw Hill Book Co. Inc. $320 \mathrm{p}$.

INSTITUTO DE PESQUISAS TECNOLÓGICAS DO ESTADO DE SÃO PAULO - IPT. Ensaio Geofísico de Magnetometria Aplicado à Localização de Tubo Metálico no Dique de Ponunduva na Região de Pirapora do Bom Jesus, São Paulo. São Paulo: IPT, 2004. (Rel. IPT N ${ }^{\circ}$ 68.619).

NABIGHIAN, M.N., 1972. The analytic signal of twodimensional magnetic bodies with polygonal crosssection: its properties and use for automated anomaly interpretation. Geophysics. Vol. 61, n? 3, p. 507-517.

STANLEY, J.M., 1977. Simplified magnetic interpretation of the geologic contact and thin dike. Geophysics. Vol. 42, n? 6, p. $1236-1240$. 